\title{
Noninvasive ventilation initiation in clinical practice: A six-year prospective, observational study
}

\author{
Chris Harris RRT ${ }^{1}$, Refik Saskin MSc ${ }^{2}$, Karen EA Burns MD FRCPC MSc ${ }^{3,4}$
}

\begin{abstract}
C Harris, R Saskin, KEA Burns. Noninvasive ventilation initiation in clinical practice: A six-year prospective, observational study. Can Respir J 2010;17(3):123-131.
\end{abstract}

BACKGROUND: Despite evidence supporting the role of noninvasive ventilation (NIV) in diverse populations, few publications describe how NIV is used in clinical practice.

OBJECTIVE: To describe NIV initiation in a teaching hospital that has a guideline, and to characterize temporal changes in NIV initiation over time. METHODS: A prospective, observational study of continuous positive airway pressure ventilation (CPAP) or bilevel NIV initiation from January 2000 to December 2005 was conducted. Registered respiratory therapists completed a one-page data collection form at NIV initiation.

RESULTS: Over a six-year period, NIV was initiated in 623 unique patients (531 bilevel NIV, 92 CPAP). Compared with bilevel NIV, CPAP was initiated more often using a nasal interface, with a machine owned by the patient, and for chronic conditions, especially obstructive sleep apnea. Whereas CPAP was frequently initiated and continued on the wards, bilevel NIV was most frequently initiated and continued in the emergency department, intensive care unit and the coronary care unit. Patients initiated on bilevel NIV were more likely to be female (OR 1.8, 95\% CI 1.08 to 2.85; $\mathrm{P}=0.02$ ) and to have an acute indication compared with CPAP initiations (OR 7.5, 95\% CI 1.61 to $34.41 ; \mathrm{P}=0.01$ ). Bilevel NIV was initiated more often in the emergency department than in the intensive care unit (OR 5.8, 95\% CI 0.89 to 38.17 ; $\mathrm{P}=0.07$ ). Bilevel NIV initiation increased from 2000 to 2005.

CONCLUSIONS: The present study illustrates how NIV is used in clinical practice and confirms that NIV initiation has increased over time.

Key Words: Acute respiratory failure; Cohort study; Mechanical ventilation; Noninvasive ventilation; Positive pressure respiration

$\mathrm{N}$ oninvasive ventilation (NIV) provides an alternative option to the initiation of invasive mechanical ventilation in patients with acute respiratory failure (ARF). It enables clinicians to provide ventilatory support to patients while instituting medical management to reverse the conditions precipitating respiratory failure. Meta-analyses strongly support the use of NIV as an initial treatment in specific etiologies of ARF including severe exacerbations of chronic obstructive pulmonary disease (COPD) (1) and congestive heart failure (CHF) (2). The evidence supporting the use of NIV - in addition to standard therapy - in patients with hypoxemic respiratory failure, is less convincing, demonstrating reductions in endotracheal intubation rate, intensive care unit (ICU) length of stay and mortality amid significant heterogeneity (3), in weaning (4) and in postextubation respiratory failure $(5,6)$. Further evidence is required to clarify the role of NIV in these circumstances.

\section{L'amorce d'une ventilation non envahissante en pratique clinique : Une étude d'observation prospective de six ans}

\begin{abstract}
HISTORIQUE : Malgré les données probantes étayant le rôle de la ventilation non envahissante (VNI) dans diverses populations, peu de publications décrivent son mode d'utilisation en pratique clinique.

OBJECTIF : Décrire l'amorce de la VNI dans un hôpital d'enseignement doté de lignes directrices et caractériser les changements temporels à cet égard au fil du temps.

MÉTHODOLOGIE : Les chercheurs ont mené une étude prospective d'observation de la pression positive continue (PPC) ou de l'amorce de la VNI à deux niveaux entre janvier 2000 et décembre 2005. Des inhalothérapeutes agréés ont rempli un formulaire de collecte de données d'une page à l'amorce de la VNI.

RÉSULTATS : Sur une période de six ans, la VNI a été amorcée chez 623 patients différents ( $531 \mathrm{VNI}$ à deux niveaux, 92 PPC). Par rapport à la VNI à deux niveaux, la PPC était davantage amorcée à l'aide d'un dispositif nasal, d'un appareil appartenant au patient ou en réponse à une maladie chronique, notamment l'apnée obstructive du sommeil. La PPC était plus amorcée et poursuivie en milieu hospitalier, mais la VNI à deux niveaux l'était davantage à l'urgence, à l'unité de soins intensifs et à l'unité de soins coronariens. Les patients chez qui on a amorcé la VNI à deux niveaux étaient plus susceptibles d'être des femmes (RRR 1,8, 95 \% IC 1,08 à 2,85; P=0,02) et d'avoir une indication aiguë que ceux chez qui on a amorcé la PPC (RRR 7,5, $95 \%$ IC 1,61 à 34,$41 ; \mathrm{P}=0,01)$. La VNI à deux niveaux était plus fréquente à l'urgence qu'à l'unité de soins intensifs (RRR 5,8, 95 \% IC 0,89 à 38,17; $\mathrm{P}=0,07)$. L'amorce de la VNI à deux niveaux a augmenté entre 2000 et 2005. CONCLUSIONS : La présente étude illustre le mode d'utilisation de la VNI en pratique clinique et confirme qu'elle est davantage amorcée au fil du temps.
\end{abstract}

Despite increasing evidence supporting the role of NIV in specific populations in well-designed studies, few publications describe how NIV is actually used in clinical practice outside of the controlled clinical trial setting. Even fewer publications describe NIV use in the presence of a clinical practice guideline. Guidelines differ from protocols, which provide a set of sequential steps to standardize patient care and policies that are not necessarily based on best current evidence. Whereas, policies and protocols are often locally developed documents that involve administrative stakeholders (7), guidelines can be nationally or locally developed and modified. Guidelines represent systematically developed statements that integrate the best current evidence to guide clinicians in the care of patients for specific clinical circumstances (7).

Experiences with NIV in clinical practice may not mirror those in clinical trials because patients in clinical practice are

${ }^{1}$ Department of Respiratory Therapy, London Health Sciences Centre, London; ${ }^{2}$ Institute for Clinical Evaluative Sciences; ${ }^{3}$ Interdepartmental Division of Critical Care, St Michael's Hospital and the "Keenan Research Centre and Li Ka Shing Knowledge Institute, Toronto, Ontario

Correspondence: Mr Chris Harris, Department of Respiratory Therapy, London Health Sciences Centre - University Hospital,

339 Windermere Road, London, Ontario N6A 5A5. Telephone 519-685-8500 ext 35069, fax 519-663-3286,

e-mail chris.harris@lhsc.on.ca 
less highly selected; interventions are applied, titrated and discontinued by staff with variable interest and expertise in their application; and monitoring is less rigorous (8). For these reasons, the results attained in clinical trials may not be realized in practice. The objectives of the present prospective, observational study were to describe how bilevel NIV is initiated in a university-affiliated teaching hospital that has a guideline for NIV initiation in place, and to characterize temporal changes in NIV initiation over time.

\section{METHODS}

\section{Study design}

A prospective, observational study of NIV initiation in a quaternary care centre over a six-year period from January 2000 to December 2005 was conducted. Episodes of NIV included initiation of continuous positive airway pressure ventilation (CPAP) or bilevel NIV. Registered respiratory therapists (RRTs) completed a one-page standardized data collection form at each NIV initiation (Appendix 1). The Research Ethics Board of the University of Western Ontario (London, Ontario) approved conduct of the present study.

\section{Setting}

The present study was conducted in a quaternary care, universityaffiliated teaching hospital in Canada. RRT members of the Department of Respiratory Therapy (London Health Sciences Centre, London, Ontario) were responsible for NIV initiation. A physician's order was required for NIV (either CPAP or bilevel) initiation. The type of NIV initiated and the initial settings were determined either by the RRT or in collaboration with a physician. While any physician could request NIV, an institutional guideline implemented early in the study period (April 2000) mandated a consultation with either the departments of pulmonary or critical care medicine to provide direction in cases for which NIV could be initiated and continued for supportive care (Appendix 2).

\section{Population}

All patients in whom NIV (either CPAP or bilevel) was initiated were included. Patients could be included in the present study on more than one occasion if they experienced separate episodes of respiratory failure necessitating NIV during the same hospital admission or during separate hospital admissions.

\section{Data collection}

A data collection form was developed to collect demographic data and highlight features of NIV initiation including initiation location (eg, ICU, coronary care unit [CCU], extended ICU, emergency department [ED], multiorgan transplant unit, neuro-observation unit or in 'other' locations), and the date of initiation and discontinuation. A cardiac surgical recovery unit was opened in April 2005, and the data collection form was modified to include the cardiac surgical recovery unit as a potential site of NIV initiation. The data form documented information regarding the reason for initiation of treatment including one or more of obstructive sleep apnea (OSA), neuromuscular weakness, COPD exacerbation, chest wall deformity, CHF, central sleep apnea, central hypoventilation syndrome or ARF. Information to characterize features of NIV initiation including the initial level of inspiratory positive airway pressure (IPAP) and expiratory positive airway pressure (EPAP), or CPAP, the initial mode used (spontaneous, timed or spontaneous/timed) and the fractional concentration of oxygen used at the time of NIV initiation, were gathered. Moreover, information regarding the nature of the application (acute versus chronic), proprietary ownership of the NIV machine (patient versus hospital), the type of interface used (nasal versus face mask) and whether the admitting service or an RRT requested the consultation with either the pulmonary or critical care departments, were collected. Finally, information related to patient outcomes including intubation, death, transfer to an alternate site for continued treatment and immediate or late NIV discontinuation outcome, was recorded. One author $(\mathrm{CH})$ retrospectively reviewed charts for patients with incomplete or missing data to ascertain information regarding patient outcomes.

\section{Statistical analysis}

Descriptive statistics including means $( \pm$ SDs) and proportions for continuous and binary measures, respectively, were reported. The median duration of NIV use was reported with its associated interquartile range. Continuous measures were compared using the Student's $t$ test, and binary outcomes using either the $\chi^{2}$ test or Fisher's exact test when expected values were less than five. A $\mathrm{P} \leq 0.05$ was considered to be statistically significant. Associations between CPAP and bilevel NIV use over time were assessed using the $\chi^{2}$ test. First-time initiations, representing independent events in statistical analyses describing the characteristics of NIV initiation, sites of NIV initiation and continued use, and the initiation of NIV over time between groups initiated on CPAP and bilevel NIV, were considered. Finally, a multivariate analysis was performed using generalized estimating equations to compute the OR and $95 \%$ CIs of bilevel NIV initiation based on age, sex, chronicity of the clinical condition, the etiology of respiratory failure, location of initiation and year of initiation compared with CPAP initiation. All analyses were performed using SAS version 9.1 (SAS Institute, USA).

\section{RESULTS}

Over the six-year observation period, NIV was initiated on 685 occasions ( 588 bilevel NIV, 97 CPAP). NIV was initiated on at least one occasion in 623 patients (531 bilevel NIV, 92 CPAP initiations). Of these, NIV was initiated in 568 patients on one occasion, 49 patients on two occasions, and on three or more occasions in six patients.

\section{Characteristics of NIV initiation}

Considering all first-time NIV initiations ( $n=623)$, the average age of patients in whom bilevel NIV was initiated was significantly greater than those in whom CPAP was initiated $(71.8 \pm 14.2$ years versus $61.1 \pm 12.5$ years, respectively). Compared with bilevel NIV, CPAP was initiated significantly more often in men than in women $(50.1 \%$ versus $83.7 \%$, respectively; $\mathrm{P}<0.001$ ). Significant differences among the reasons for initiation of CPAP and bilevel NIV were found. While bilevel NIV was most often initiated for ARF, CHF and COPD $(52.2 \%, 36.9 \%$ and $15.4 \%$ of first-time initiations, respectively), CPAP was largely initiated for OSA ( $85.9 \%$ of first-time initiations). Bilevel NIV was infrequently initiated for neuromuscular weakness, OSA, central hypoventilation, central 
TABLE 1

Features of noninvasive ventilation initiation

\begin{tabular}{lccc}
\hline Parameter & CPAP (n=92) & Bilevel (n=531) & P \\
\hline Sex, $\mathbf{n}$ (\% male) & $77(83.7)$ & $266(50.1)$ & $<0.001$ \\
Age, years & & & \\
$\quad<65$ & $56(60.9)$ & $136(25.6)$ & $<0.001$ \\
65 to 79 & $31(33.7)$ & $219(41.2)$ & \\
$>79$ & $5(5.4)$ & $176(33.2)$ & \\
Interface & & & \\
$\quad$ Nasal & $76(82.6)$ & $15(2.8)$ & $<0.001$ \\
Face mask & $16(17.4)$ & $516(97.2)$ & \\
Machine & & & \\
Patient owned & $37(40.2)$ & $4(0.7)$ & $<0.001$ \\
$\quad$ Hospital & $55(59.8)$ & $527(99.3)$ & \\
Chronic use & $78(84.8)$ & $42(7.9)$ & $<0.001$ \\
Consultation requested by & & & \\
$\quad$ None & $3(3.2)$ & $16(3.0)$ & 0.25 \\
RRT & $39(42.4)$ & $169(31.8)$ & \\
Admitting team & $48(52.2)$ & $329(62.0)$ & \\
Both RRT and admitting team & $2(2.2)$ & $17(3.2)$ & \\
\hline
\end{tabular}

Data presented as $n$ (\%) unless indicated otherwise. CPAP Continuous positive airway pressure; RRT Registered respiratory therapist

apnea and chest wall disorders. Patients treated with bilevel NIV were initiated on a higher fractional concentration of oxygen than patients initiated on CPAP $(65.8 \pm 28.8$ versus $33.3 \pm 19.3$; $\mathrm{P}<0.001)$. Average IPAP and EPAP levels used to initiate bilevel NIV were $11.5 \pm 2.3 \mathrm{cmH}_{2} \mathrm{O}$ and $5.7 \pm 1.4 \mathrm{cmH}_{2} \mathrm{O}$, compared with $8.9 \pm 2.6 \mathrm{cmH}_{2} \mathrm{O}$ in CPAP patients with significant differences in end-expiratory pressure between groups $(\mathrm{P}<0.001)$. Bilevel NIV was almost exclusively initiated in timed mode $(99.4 \%)$. The features pertaining to NIV initiation are presented in Table 1.

Sites of NIV initiation and continued use

Locations of NIV initiation and continued use are summarized in Table 2. Whereas CPAP was most frequently initiated and continued in 'other' locations, primarily on the wards, bilevel NIV was most frequently initiated and continued in the ICU, $\mathrm{ED}$ and $\mathrm{CCU}$.

\section{Initiation of NIV over time}

Figure 1 depicts temporal trends in CPAP and bilevel NIV initiation. While the proportion of CPAP initiations exceeded bilevel NIV initiations from 2000 to 2003, bilevel NIV was initiated more frequently than CPAP thereafter, although the rate was not constant. Regarding indication for initiation, consistent increases in bilevel NIV initiation between 2000 and 2005 were noted for episodes of ARF and exacerbations of COPD.

\footnotetext{
Multivariate analysis

In the multivariate analysis, women were more likely than men to undergo bilevel NIV initiation (OR 1.8, 95\% CI 1.08 to 2.85; $\mathrm{P}=0.02$ ). Bilevel NIV was more likely to be initiated in the ED than in the ICU (OR 5.8, 95\% CI 0.89 to 38.17; $\mathrm{P}=0.07$ ) and more often initiated for acute than for chronic conditions (OR 7.5, 95\% CI 1.61 to 34.41; $\mathrm{P}=0.01$ ). Compared with CPAP initiation, significant differences were not found in bilevel NIV initiation among patients between 65 and 79 years of age, and those older than 79 years of age (using the 65 years of age and younger group as the referent category). Compared
}

TABLE 2

Locations of noninvasive ventilation initiation and continued use

\begin{tabular}{lccccc}
\hline & \multicolumn{2}{c}{ Initiation } & & \multicolumn{2}{c}{ Continued use } \\
\cline { 2 - 3 } \cline { 6 - 7 } Location & $\begin{array}{c}\text { CPAP } \\
(\mathbf{n}=\mathbf{9 2})\end{array}$ & $\begin{array}{c}\text { Bilevel } \\
(\mathbf{n}=531)\end{array}$ & & $\begin{array}{c}\text { CPAP } \\
(\mathbf{n}=92)\end{array}$ & $\begin{array}{r}\text { Bilevel } \\
(\mathbf{n}=531)\end{array}$ \\
\hline Emergency department & $5(5.4)$ & $142(26.7)$ & & - & $98(18.5)$ \\
ICU & $19(20.7)$ & $157(29.6)$ & & $10(10.9)$ & $207(39.0)$ \\
Coronary care unit & $11(12.0)$ & $94(17.7)$ & & $11(12.0)$ & $103(19.4)$ \\
Extended ICU & $1(1.1)$ & $7(1.3)$ & & & $5(0.9)$ \\
Cardiac surgery & $2(2.2)$ & $16(3.0)$ & & $2(2.2)$ & $18(3.4)$ \\
$\quad$ recovery unit & & & & & \\
Multiorgan transplant & $3(3.3)$ & $31(5.8)$ & & $2(2.2)$ & $30(5.7)$ \\
$\quad$ unit & & & & & \\
Neuro-observation unit & $4(4.4)$ & $24(4.5)$ & & $3(3.3)$ & $19(3.6)$ \\
Other locations & $47(51.1)$ & $60(11.3)$ & & $64(69.6)$ & $51(9.6)$ \\
\hline
\end{tabular}

Data presented as $n$ (\%). CPAP Continuous positive airway pressure; ICU Intensive care unit

with CPAP, patients were less likely to undergo bilevel NIV initiated for OSA (OR 20, 95\% CI 4.76 to 100; P $\leq 0.001$ ) using $\mathrm{COPD}$ as the referent category. Bilevel NIV was more likely to be initiated in 2005 compared with 2000 (OR 32.5, 95\% CI 1.07 to $982.56 ; \mathrm{P}=0.045$ ).

\section{Processes and outcomes}

The admitting team requested either pulmonary or critical care consultations, in accordance with the institutional guideline (48 of 92 [52.2\%] and 329 of 531 [62.0\%] for CPAP and bilevel NIV initiation, compared with 39 of 92 [42.4\%] and 169 of 531 [31.8\%] for consultations requested by RRTs). A consultation was not requested by either service in 19 (6.2\%) of first-time initiations. Patients were infrequently continued on bilevel NIV (110 of 531 [20.7\%]) and CPAP (21 of 92 [22.8\%]) during transfer to sites of continued treatment.

More bilevel-treated patients underwent early discontinuation (shortly after initiation) than CPAP-treated patients (24 of 531 [4.5\%] versus two of 92 [2.2\%]; $\mathrm{P}=0.30$ ); $\mathrm{CPAP}$ was rarely discontinued at later time points (16 of 92 [17.4\%]). Compared with CPAP-treated patients, more bilevel-treated patients required intubation (three of 92 [3.3\%] versus 124 of 531 [23.4\%]; $\mathrm{P}<0.001$ ) and died (one of 92 [1.1\%] versus 26 of 531 [4.9\%]; $\mathrm{P}=0.10$ ) during hospitalization.

\section{DISCUSSION}

We found several important differences in how, where and in whom CPAP and bilevel NIV were initiated in our observational study. Compared with bilevel NIV, CPAP was initiated more often using a nasal interface - with a machine owned by the patient - and for chronic conditions, especially OSA. Bilevel NIV was most often initiated for ARF, CHF and exacerbations of COPD. Whereas CPAP was most frequently initiated and continued in other locations - primarily on the wards - bilevel NIV was most frequently initiated and continued in the ICU, ED and CCU. Compared with CPAP, patients initiated on bilevel NIV were 1.8 times more likely to be female (95\% CI 1.08 to 2.85; $\mathrm{P}=0.02$ ) and 7.5 times more likely to have an acute condition (95\% CI 1.61 to $34.41 ; \mathrm{P}=0.01$ ). Bilevel NIV was 5.8 times more likely to be initiated in the ED than in the ICU $(95 \%$ CI 0.89 to 38.17; $\mathrm{P}=0.07$ ) and 20 times less likely to be initiated for OSA than for CPAP (95\% CI 4.76 to $100 ; \mathrm{P} \leq 0.001$ ). We found a significant association between bilevel NIV initiation and time, 


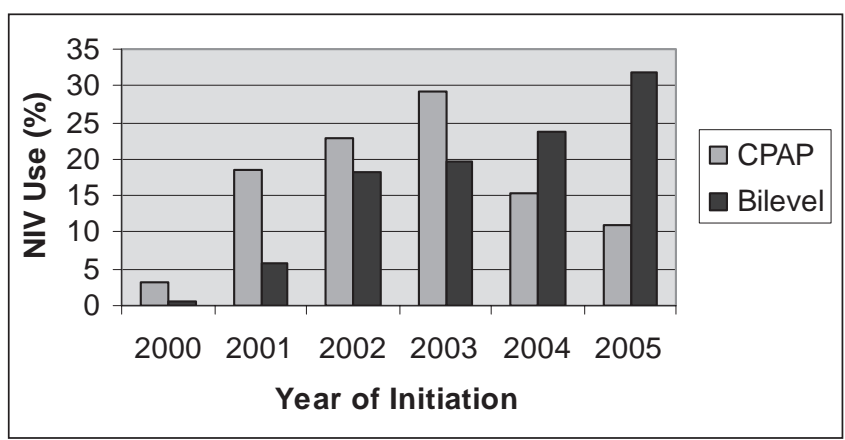

Figure 1) Frequency of noninvasive ventilation (NIV) initiation over time at the London Health Sciences Centre, London, Ontario. CPAP Continuous positive airway pressure

with bilevel NIV being 32.5 times more likely to be initiated in 2005 than in 2000 (95\% CI 1.07 to 982.56; P=0.045) (Table 3). These findings provide insight into how bilevel NIV is initiated in a teaching hospital that has a guideline in place, and characterizes temporal changes in NIV initiation over time.

The present study has several strengths. First, it is the largest observational study conducted to date focusing on NIV initiation in practice. Second, the study highlighted important differences in how, where and in whom NIV is initiated in a teaching hospital with a guideline in place to direct its use. Third, our study demonstrated that bilevel NIV initiation increased significantly between 2000 and 2005 amid increasing literature supporting the benefits of NIV use in specific populations.

Our prospective cohort study, however, also has weaknesses. First, RRTs collected a minimum dataset on a standardized one-page data collection form each time NIV was initiated. While the minimum data set was designed to address the primary research question, it did not contain additional information to describe illness severity at the time of NIV initiation. Second, we included ARF among our indications for NIV initiation, recognizing that clinicians may be unable to accurately characterize the principal etiology of respiratory failure at the time of NIV initiation. Consequently, RRTs could have selected more than one diagnostic category at the time of NIV initiation. Our prospective data collection, therefore, mirrors the clinical uncertainty that exists in ascribing a single etiology of respiratory failure at the time of NIV initiation. Third, consistent with the research question posed, we did not limit our data collection to patients with ARF, making direct comparisons of our study population to those in the literature difficult. Finally, we retrospectively reviewed charts with missing information to ascertain information regarding outcomes. Despite attempts to ensure uniformity (eg, a single author reviewing charts), data abstraction may have been subject to recall bias.

Our results share both common features and differences with other prospective (9) and retrospective $(10,11)$ observational studies of NIV use in clinical practice. Similar to Paus-Jenssens et al (9), who reported on 75 NIV initiations in 71 patients (bilevel NIV [85\%] and CPAP [15\%]), we noted that $85.8 \%$ and of all NIV initiations and $85.2 \%$ of first-time NIV initiations involved bilevel NIV. With regard to initial application, we noted that CPAP was most often initiated with a nasal mask, while bilevel NIV was usually initiated with a face mask.
TABLE 3

Estimates of bilevel noninvasive ventilation initiation

\begin{tabular}{|c|c|c|}
\hline Variable & OR $(95 \% \mathrm{Cl})$ & $\mathbf{P}$ \\
\hline \multicolumn{3}{|l|}{ Age, years } \\
\hline$<65$ & 1.00 & - \\
\hline $65-79$ & $1.20(0.49-2.93)$ & 0.686 \\
\hline$>80$ & $1.57(0.35-7.10)$ & 0.560 \\
\hline \multicolumn{3}{|l|}{ Sex } \\
\hline Male & 1.00 & - \\
\hline Female & $1.76(1.08-2.85)$ & 0.022 \\
\hline \multicolumn{3}{|l|}{ Condition } \\
\hline Chronic & 1.00 & - \\
\hline Acute & $7.45(1.61-34.41)$ & 0.010 \\
\hline \multicolumn{3}{|l|}{ Reason for initiation } \\
\hline Chronic obstructive pulmonary disease & 1.00 & - \\
\hline Obstructive sleep apnea & $0.05(0.01-0.21)$ & $<0.001$ \\
\hline Congestive heart failure & $2.74(0.54-13.85)$ & 0.222 \\
\hline Neuromuscular & $3.87(0.79-18.9)$ & 0.094 \\
\hline Central apnea & $0.93(0.15-5.78)$ & 0.935 \\
\hline Central hypoventilation & $1.4(0.08-23.10)$ & 0.815 \\
\hline Acute respiratory failure & $0.86(0.25-3.00)$ & 0.814 \\
\hline \multicolumn{3}{|l|}{ Initiation site } \\
\hline Intensive care unit & 1.00 & - \\
\hline Emergency department & $5.82(0.89-38.17)$ & 0.067 \\
\hline Coronary care unit & $1.49(0.44-5.00)$ & 0.519 \\
\hline Extended intensive care unit stay & $0.83(0.05-14.05)$ & 0.899 \\
\hline Multiorgan transplant & $1.50(0.46-4.87)$ & 0.496 \\
\hline Neuro-observation & $1.68(0.31-9.11)$ & 0.549 \\
\hline Other & $0.40(0.12-1.39)$ & 0.152 \\
\hline \multicolumn{3}{|l|}{ Year of initiation } \\
\hline 2000 & 1.00 & - \\
\hline 2001 & $8.14(0.21-317.58)$ & 0.262 \\
\hline 2002 & $17.25(0.48-620.42)$ & 0.119 \\
\hline 2003 & $16.54(0.54-508.30)$ & 0.108 \\
\hline 2004 & $9.58(0.3-304.46)$ & 0.200 \\
\hline 2005 & 32.47 (1.07-982.56) & 0.045 \\
\hline
\end{tabular}

Our results are similar to those of Girault et al (10), who found that a face mask was the preferred interface in $81 \%$ of bilevel NIV initiations in 143 NIV episodes. Initial IPAP and EPAP levels in our study ( $11.5 \mathrm{cmH}_{2} \mathrm{O}$ and $5.7 \mathrm{cmH}_{2} \mathrm{O}$, respectively) were also similar to those reported by Paus-Jenssens et al (9) $\left(12 \mathrm{cmH}_{2} \mathrm{O}\right.$ and $\left.6 \mathrm{cmH}_{2} \mathrm{O}\right)$ and Sinuff et al (11) $\left(10.0 \mathrm{cmH}_{2} \mathrm{O}\right.$ and $5.0 \mathrm{~cm} \mathrm{H}_{2} \mathrm{O}$ ).

We found that bilevel NIV was most frequently initiated in the ED and the ICU, while CPAP was most frequently initiated in other locations and the ICU. To this end, Paus-Jenssens et al (9) noted that CPAP and bilevel NIV were most often initiated in the ED (32\%), a critical care setting (27\%) or on general medical/surgical wards, or wards with an observation unit (41\%). Whereas Sinuff et al (11) noted that bilevel NIV was predominantly initiated in the ED (62.1\% of trials), we found that it was most often initiated in the ED and the ICU. Conversely, while bilevel NIV was frequently administered on clinical teaching units in their study $(20.2 \%)$, we found that bilevel NIV was infrequently continued in other locations $(9.5 \%)(11)$. Similar to the findings of Sinuff et al (11), in which $33.7 \%$ of patients were transferred to the ICU for bilevel NIV treatment in a postguideline implementation study, we noted that bilevel NIV was continued in the ICU in 39\% of patients (12). In contrast, we observed that the majority of 
initiations (93.8\%) had consultations with either the department of pulmonary or critical care medicine - as directed by the guideline - versus $49 \%$ of patients in their study (12).

Similar to other investigations, we found that CHF and COPD were prominent indications for bilevel NIV initiation $(8,13-15)$. While our guideline did not specify in which patient populations NIV could be initiated, we initiated NIV in a comparatively smaller proportion of patients with diagnoses of CHF (44.2\% versus 36.9\%) and COPD (24.2\% versus $15.4 \%)$. We postulate that this may be related to differences in data collection, with data in other studies being collected retrospectively and our data being captured at NIV initiation. Our clinical diagnoses were made in advance of continued patient observation and knowledge of response to treatment. Consequently, our indications for initiation may underestimate the prevalence of specific clinical conditions. Finally, our intubation rate of $23.4 \%$ of bilevel NIV initiations, while similar to that of Sinuff et al (11) (25.6\%), is higher than that reported by Paus-Jenssens et al (9) (13\%) and substantially lower than that reported by Girault et al (10) (38\%). These findings suggest that NIV may be initiated in different patient populations with different illness severity at presentation. In summary, our findings are similar to those of previous investigations with regard to characteristics and frequency of NIV initiation, sites of initiation and the predominant reasons for NIV initiation, but differ in sites of continued use and outcomes achieved.

Several important observations can be made from our study. While our guideline for NIV initiation did not mandate that NIV be continued in specific locations, it prioritized consultation with either pulmonary or critical care medicine following NIV initiation. The consultative team, in collaboration with the admitting team and RRTs, assessed the patient's clinical status, RRT accessibility and nursing expertise in deciding whether a monitored bed was required on a case-by-case basis. These decisions indicated the sites for continued NIV administration. We observed a high degree of compliance with our guideline in the requirement for a consultation, with a substantial proportion of consults requested by RRTs, and identified monitored settings for continued bilevel NIV treatment. Many guidelines exist, but fail in practice because they are not actively implemented or endorsed by end users. Our guideline provided sufficient structure to bring together key stakeholders to evaluate whether NIV could be safely continued in specific patients and locations within our hospital. In addition, it prioritized the collaborative role of admitting teams, RRTs and consultative services in working together to ensure appropriate patient disposition. Factors contributing to the successful implementation of our guideline in clinical practice include its multidisciplinary nature, and that it encouraged interaction among health care providers and was championed locally by RRTs.

Finally, our NIV initiation study confirmed that bilevel NIV initiation has increased significantly over time, although the rate has not been constant (15). Many patients in our study may have required ICU monitoring regardless of NIV initiation. Notwithstanding, while NIV use may be increasing over time, the availability of monitored beds to meet this demand has not risen commensurately. This presents clinicians involved with using NIV with a challenge that may impede appropriate and safe NIV use (16). While it may be justifiable to continue CPAP - a technology frequently managed by patients in the domiciliary setting on hospital wards sufficient resources should be available to enable clinicians to provide bilevel NIV in areas with enhanced monitoring capacity and appropriately trained personnel. Further prospective study is required to characterize the intensity of monitoring required for patients initiated on NIV.

ACKNOWLEDGEMENT: The authors thank the respiratory therapists at University Hospital (London, Ontario) for their dedicated efforts with data collection.

CONFLICT OF INTEREST: The authors have no competing interests to declare.

DISCLOSURE: None of the authors has a financial relationship with a commercial entity that has an interest in the subject of the manuscript.

FUNDING: Dr Karen EA Burns holds a Clinician Scientist award from the Canadian Institutes of Health Research.

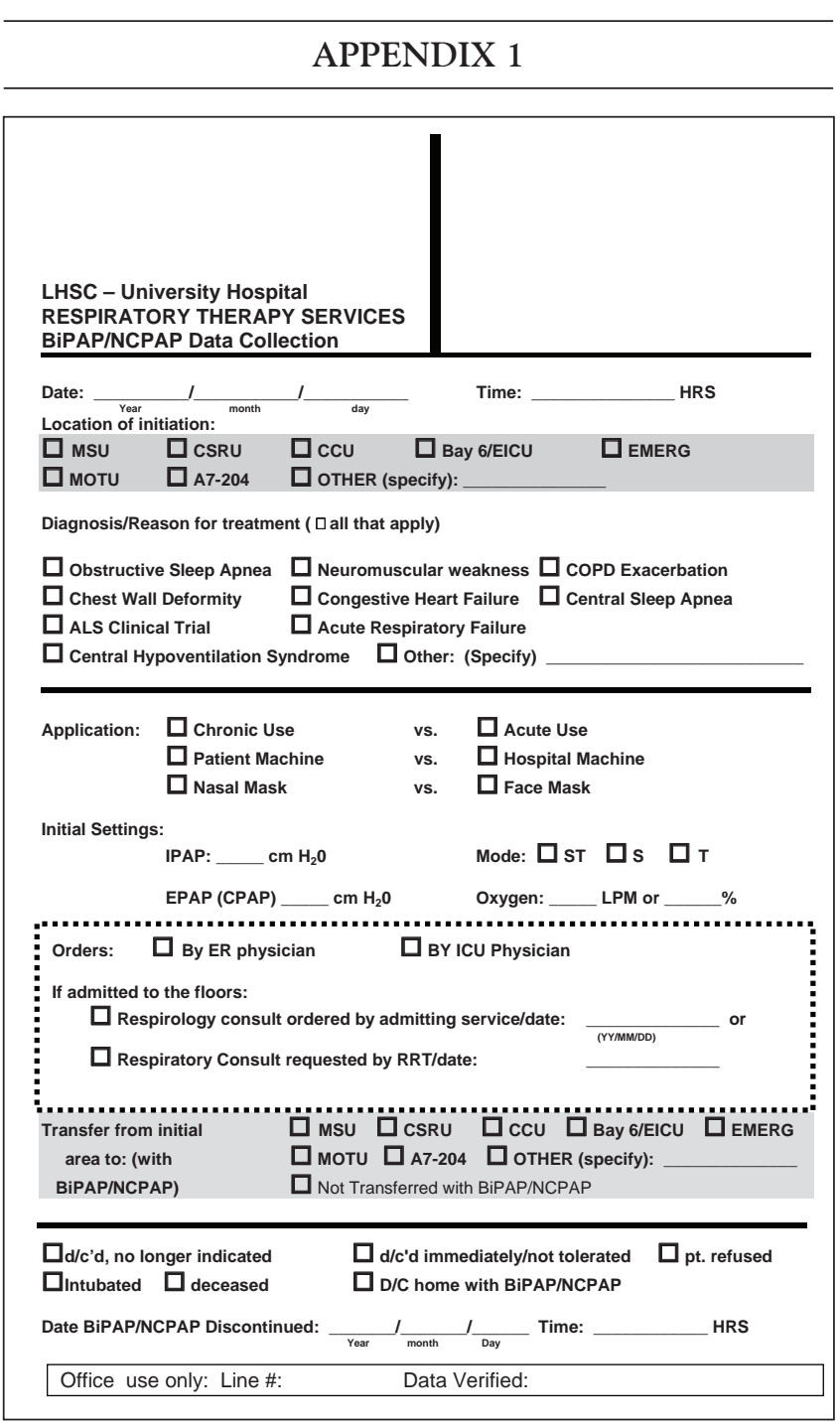




\section{Non-invasive Ventilation Guidelines (External to the ICU)}

\begin{tabular}{l|l|l|}
\hline Section: & Patient Care \\
\hline Policy \#: & PCC033 \\
\hline Responsibility: & Chair, Medical Advisory Committee \\
\hline
\end{tabular}

This document is a GUIDELINE, not a policy.

\section{BACKGROUND}

The use of noninvasive positive pressure ventilation, the delivery of positive pressure mechanical ventilation to the lungs without endotracheal intubation, is increasing among patients with acute and chronic respiratory failure. This is due, in part, to its relative ease of use, lower costs and morbidity-sparing potential compared with standard invasive positive pressure ventilation.

For the purpose of this guideline, non-invasive ventilation refers to non-invasive positive pressure

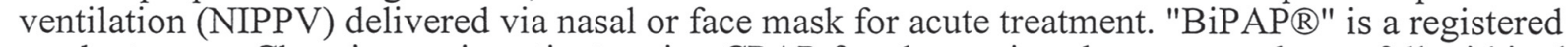
product name. Chronic use, ie patients using CPAP for obstructive sleep apnea, do not fall within the parameters of this guideline.

Non-invasive positive pressure ventilatory support modes are designed to provide inspiratory and/or expiratory positive airway pressure. It is a temporary therapy which supports the patient until the underlying cause is recognized and, if possible, treated.

NIPPV is a mode of ventilation which augments breathing- it is not a life support mode. Any patient on NIPPV must be able to sustain their own spontaneous ventilation. NIPPV can help the patient by decreasing the work of breathing, improving ventilation, promoting improved oxygenation and opening and maintaining the stability of the airways.

\section{Indications for the use of non-invasive ventilation:}

NIPPV is an option for patients who exhibit a need for partial ventilatory support in cases such as:

- Acute respiratory failure with associated

- Acute respiratory acidosis

- Respiratory distress

- Use of accessory muscles or paradoxical breathing

- Congestive heart failure

\section{Contraindications to the use of non-invasive ventilation}

- Inadequate respiratory drive

- Medically unstable patient (hypotensive, shock, acute MI, uncontrolled cardiac arrhythmia, uncontrolled GI bleed, rapidly progressive neuromuscular weakness)

- Unable to control airway or control secretions

- Unable to fit mask

- Uncooperative patient

- Stridor as the main cause of dyspnea

- Patient with decreased level of consciousness or restrained/immobilized 


\section{Use of non-invasive ventilation in patients who are designated as DNR}

Non invasive ventilation is not contraindicated in patients who have made the choice to have a DNR order. In this scenario, the use of non-invasive ventilation needs to be discussed with the patient and there should be clarification about the limits of resuscitation if the patient continues to deteriorate while on non-invasive ventilation.

Use of non-invasive ventilation in patients having palliative care Generally, due to the limited number of respiratory therapists in the hospital and the number of non-invasive ventilation units, the use of non invasive ventilation is not indicated in patients in this scenario. After discussion between the attending physician and the consultant respirologist there may be very unusual situations when this occurs.

Patients on acute non-invasive ventilation are cared for in designated patient care areas of LHSC and SJHC. They are:

\section{LHSC}

- $\mathrm{SSC}-4 \mathrm{MSX}$

- UC - 7 Neuro, MOTU, CCU

- Emergency Department and ICU at all campuses

\section{SJHC}

- A6

- Emergency Department and ICU

Care is restricted to these areas due to the availability of:

- nurses trained by Respiratory Therapy in care of the patient using non-invasive ventilation

- oxygen $(\mathrm{SaO} 2)$ and cardiac monitoring

Patients using non-invasive ventilation on a chronic basis at home may be managed in any area of the hospital.

\section{PURPOSE}

To ensure consistent and safe care of patients requiring non-invasive ventilation.

PROCEDURE (Also see flowchart)

Patients may be ventilated non-invasively in the Emergency Department, but when transferred out of the ER, the following procedure must be followed:

- All patients being considered for non-invasive ventilation must be referred to Respirology for a consult. The referring physician and the Respirologist will discuss the need for a monitored bed.

- The Respirologist is responsible for writing the orders for non-invasive ventilation including the maximum settings, goals of therapy and the plan for evaluation.

- The Registered Respiratory Therapist (RRT) initiates the therapy, adjusts and manages settings and assesses the patient as required, depending on the medical status of the patient. Respiratory Therapy has department-specific guidelines for monitoring of a patient on NIPPV and for the equipment used.

- The Registered Nurse monitors the ongoing therapy and assesses the patient as ordered depending on the medical status of the patient.

- If a bed in an area where the nursing staff is trained in caring for a patient with non-invasive ventilation is not available, the patient is referred to ICU for consultation and possible admission. 


\section{City-Wide Guidelines for the Use of Non-Invasive Ventilation - External to ICU}

\section{See guidelines for detaiks}

Hote: Patient may be non-invasively ventilated in the Emergency Department, but these guidelines apply upontransfer.

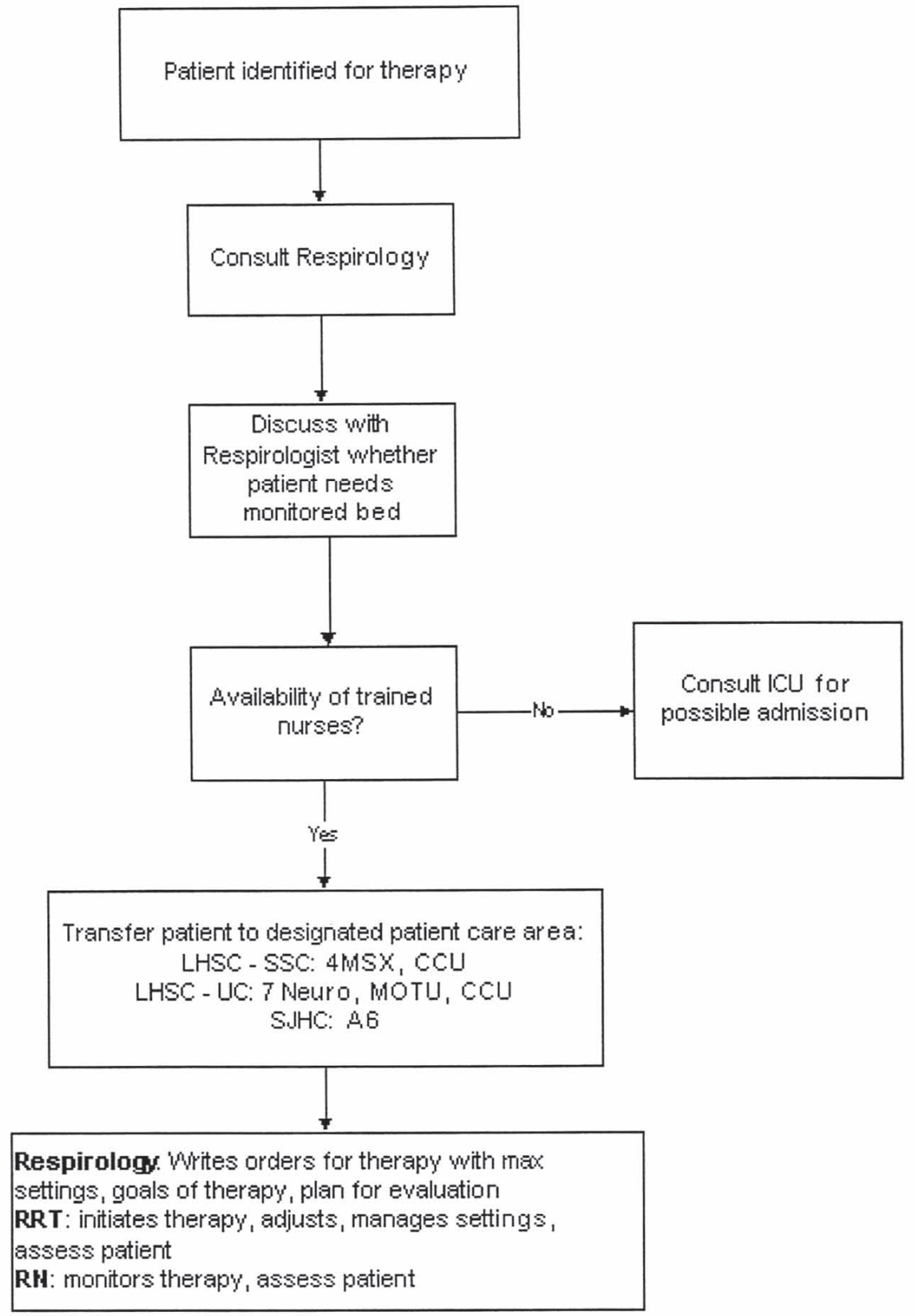

CCU Critical care unit; CPAP Continuous positive airway pressure; DNR Do not resuscitate; GI Gastrointestinal; ICU Intensive care unit; LHSC London Health Sciences Centre; MOTU Multiorgan transplant unit; MSX Middlesex; Neuro Neuro-observation unit; RN Registered nurse; RRT Registered respiratory therapist; SJHC St Joseph's Health Centre; SSC South Street Campus; UC University Campus 


\section{REFERENCES}

1. Keenan SP, Sinuff T, Cook DJ, Hill NS. Which patients with acute exacerbations of chronic obstructive pulmonary disease benefit from noninvasive positive-pressure ventilation? A systematic review of the literature. Ann Intern Med 2003;138:861-70.

2. Masip J, Roque M, Sanchez B, Fernandez R, Subirana M, Exposito JA. Noninvasive ventilation in acute cardiogenic pulmonary edema: A systematic review and meta-analysis. JAMA 2005;294:3124-30.

3. Keenan SP, Sinuff T, Cook DJ, Hill NS. Does noninvasive positive pressure ventilation improve outcome in acute hypoxemic respiratory failure? A systematic review. Crit Care Med 2004;32:2516-23.

4. Burns KE, Adhikari NK, Meade MO. Noninvasive positive pressure ventilation as a weaning strategy for intubated adults with respiratory failure. Cochrane Database Syst Review 2003:CD004127.

5. Keenan SP, Powers C, McCormick DJ, Block G. Noninvasive positive pressure ventilation for post-extubation respiratory distress: A randomized controlled trial. JAMA 2002;287:3238-44.

6. Esteban A, Frutos-Vivar F, Ferguson ND, et al. Noninvasive positive-pressure ventilation for respiratory failure after extubation. N Engl J Med 2004;350:2452-60.

7. Sinuff T, Cook DJ. Guidelines in the intensive care unit. Clin Chest Med 2003;24:739-49.

8. Burns KEA, Sinuff T, Adhikari NK, et al. Bilevel noninvasive positive pressure ventilation for acute respiratory failure: A survey of Ontario practice. Crit Care Med 2005;33:1477-83.
9. Paus-Jenssens ES, Reid JK, Cockroft DW, Laframboise K, Ward HA. The use of noninvasive ventilation in acute respiratory failure in a tertiary care centre. Chest 2004;126:165-72.

10. Girault C, Briel A, Hellot MF, et al. Noninvasive mechanical ventilation in clinical practice: A 2-year experience in a medical intensive care unit. Crit Care Med 2003;31:552-9.

11. Sinuff T, Cook DJ, Randall, Allen CG. Evaluation of a practice guideline for noninvasive positive-pressure ventilation for acute respiratory failure. CMAJ 2000;163:969-73.

12. Maheshwari V, Paioli D, Rothaar R, Hill NS. Utilization of noninvasive ventilation in acute care hospitals: A regional survey. Chest 2006;129:1226-32.

13. Sinuff T, Cook DJ, Randall J, Allen CJ. Evaluation of a practice guideline for noninvasive positive pressure ventilation for acute respiratory failure. Chest 2003;123:2062-73.

14. Kumle B, Haisch G, Suttner SW, Piper SN, Malek W, Boldt J. Current status of NIV in German ICUs: A postal survey. Anesthesiol Intensivmed Notfall Med Schmerzther 2003;38:32-7.

15. Demoule A, Girou E, Richard JS, Taille S, Brochard L. Increased use of noninvasive ventilation in French intensive care units. Intensive Care Med 2006;32:1747-55.

16. Vanpee D, Delaunois L, Lheureux P, et al. Survey of noninvasive positive pressure ventilation for chronic obstructive pulmonary disease in emergency departments in Belgium. Eur J Emerg Med 2002;9:217-24. 


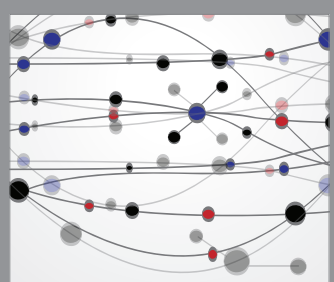

The Scientific World Journal
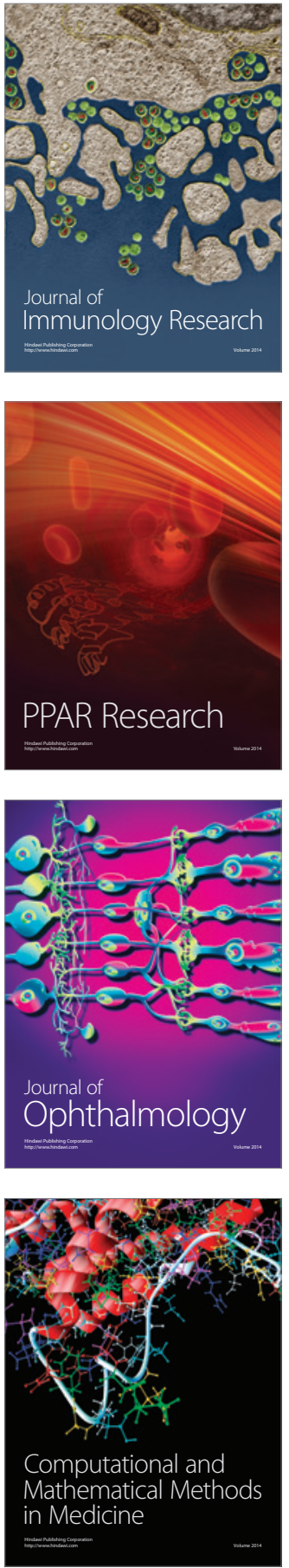

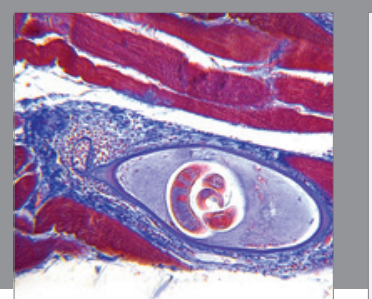

Gastroenterology Research and Practice

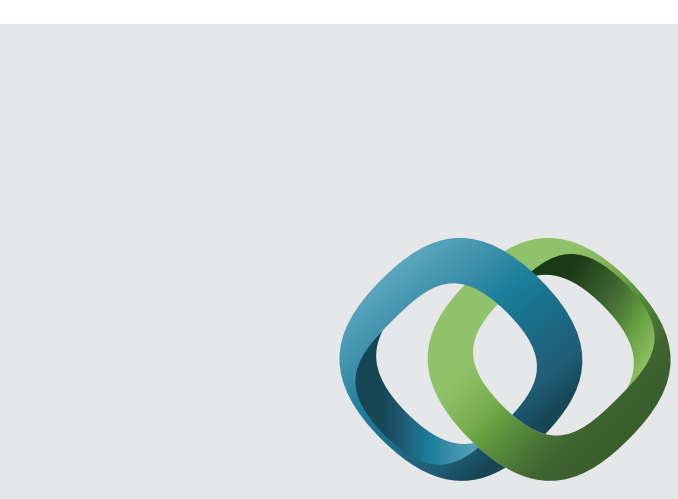

\section{Hindawi}

Submit your manuscripts at

http://www.hindawi.com
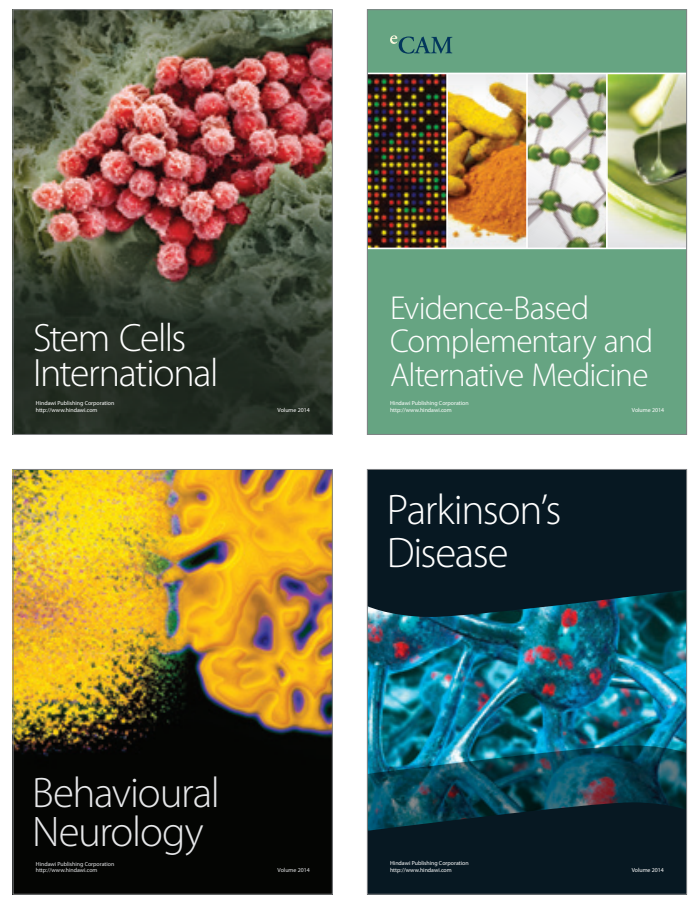
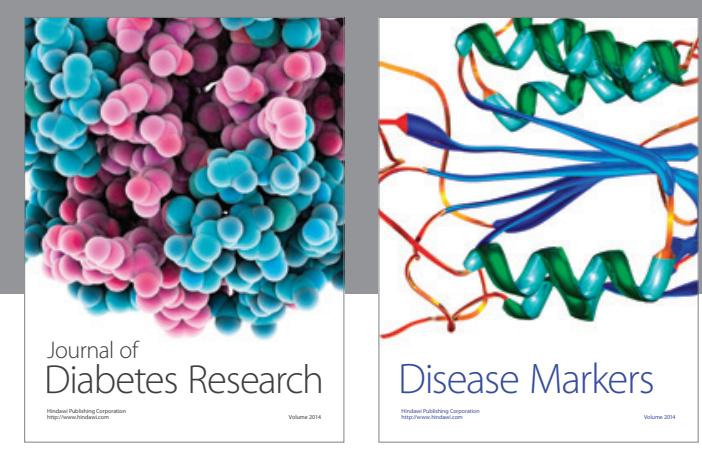

Disease Markers
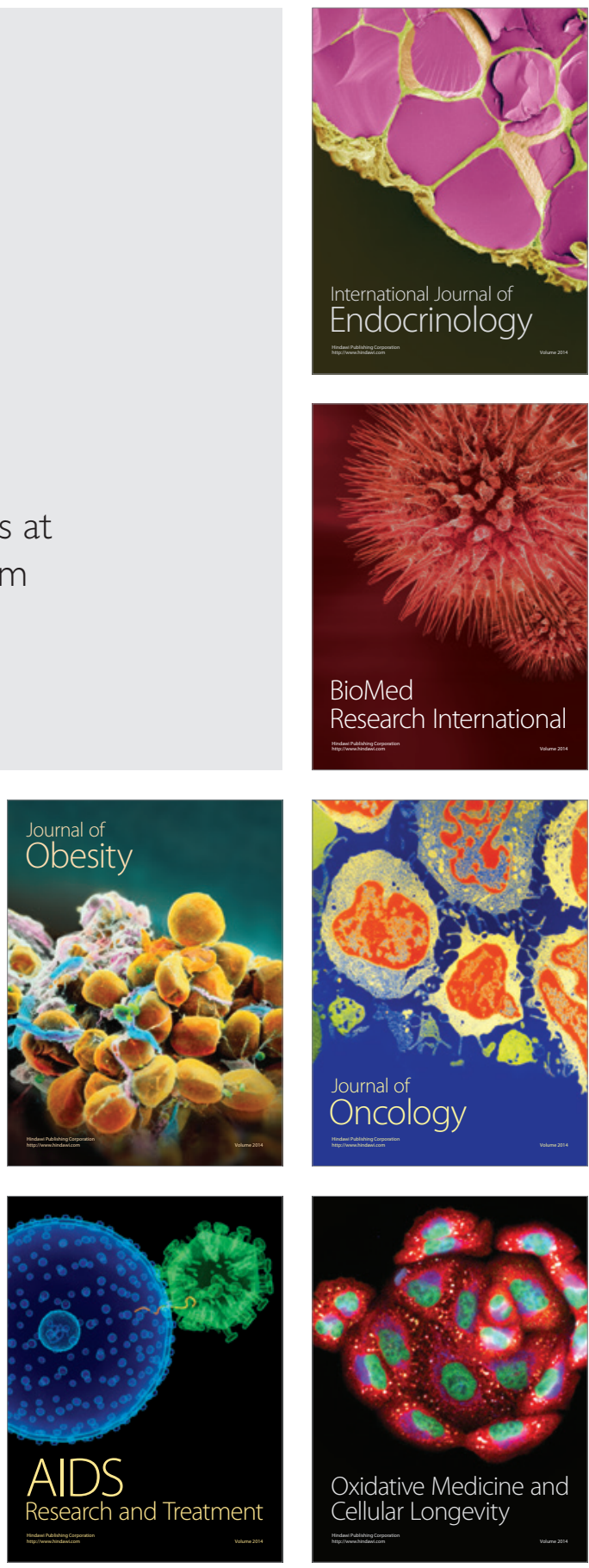